\title{
Mortar strength of Low calcium Flyashbased Geopolymer
}

\author{
${ }^{1}$ Manimaran, E and ${ }^{2}$ Mohankumar, G. \\ ${ }^{I}$ Research Scholar, PRIST University, Thanjavur. \\ ${ }^{2}$ Professor of Civil Engineering, Arunai Engineering College, Tiruvannamalai
}

\begin{abstract}
Development of an alternative to conventional cement binder has become the essential need in the construction industries. Production of the conventional constituents of concrete particularly Portland cement exploits significant amount of natural resources and emits equivalent amountof carbon dioxide to the atmosphere. Research made on making binder without cement has come to a viable level of developing geopolymers.Industrial wastes and by products that are pozzolanic in nature are being used as source material and activated using alkaline solutions to use as binder. Considerable research has been carried out to study about the performance of geopolymer concrete with steam curing or hot curing which are feasible for precast concrete and practically not viable for conventional construction activities. However, there is not much data available on themortar strength.Abasic study on the strength characteristicsof low calcium flyash based geopolymer with 8-16M molar concentration of Sodium hydroxide and 1.5-3.0 liquid ratios of sodium silicate to sodium hydroxide. Both hot oven curingat $65^{\circ} \mathrm{C}$ and ambient curing at room temperature aremade. The results are compared and the optimum molarity for maximum strength is reported.
\end{abstract}

Keywords: Geopolymer, low calcium flyash, ambient curing, hot curing, mortar strength

\section{Introduction}

The demand for concrete is increasing day by day and at the same time, the environmental aspects of concrete are being discussed to develop an eco-friendly binder. As the $\mathrm{CO}_{2} \mathrm{emission}$ and the exploitation of natural resources in producing cement and hence the concrete, lead to environmental degradation, there is a need to arrive an alternative to cement binder. Cement is an important ingredient of the conventional concrete used in centuries and responsible for binding property cannot be simply ignored. However, in 1980s, Joseph Davidovits, a French scientist initiated research on linear organic polymers and later the alumino-silicate solid state chemistry resulting in the development of new binder by polymerization called geopolymer.

Geopolymers are mineral substances obtained synthetically by chemical processes but are actually also found in nature, which take millions of years (Davidovits and Morris, 1988) to form. A hypothesis formulated about the use of geopolymer binders during the Egyptian construction of 4000 years old ancient monuments is the synthetic stones of reagglomerated materials.A mineral substance such as disintegrated or naturally disaggregated rock and giving it a compact structure using a binder, a geological glue that will agglomerate (or re-agglomerate) the mineral particles is involved. The same concrete technology was used during the erection of Egyptian pyramids by laying geopolymer mixes (with a limestone aggregate) into formwork; individual blocks were thus produced step by step. Thus, Geopolymer is basically an inorganic alumino-silicate compound, synthesized from certain source materials. Joseph Davidovits (2011) explained his pioneer works of geopolymers based on, kaolinite/hydrosodalite, metakaolin, calcium, rock, silica, flyash, phosphate and organic minerals.

The source material and the blend of sodium hydroxide (or potassium hydroxide) solution and sodium silicate (or potassium silicate) solution termed as alkaline solutionare the two important constituents of GP.Source materials like low calcium flyash (Djwantoro et al., 2003 and Rangan, 2008), GGBS (Parthiban and Saravanaraja Mohan, 2014), Metakaolin,calcium, rock, silica, flyash, phosphate and organic minerals (Joseph Davidovits, 2011), mineral powder (Huihong Liu et al, 2014), red mud with flyash and micro silica (Abhishek and Aswath, 2012) and high calciumflyash (Shankar and Khadiranaikar, 2012: Ashley Russell et al, 2015 and Prinya Chindaprasirt et al,2013) have been used in the development of GPC.Mostly used flyash that is rich in silica and alumina reacts with alkaline solution and forms aluminosilicate gel that acts as the binder and by thermal activation produces GPC.

Flyash is abundantly available, but to date its utilization is limited inspite of the specifications (IS: 3812-1981).The source material is mixed with an activating solution which liberate the $\mathrm{Si}$ and $\mathrm{Al}$ and possibly with the additional source of silica (sodium silicate). The various parameters that influence include, ratio of alkaline liquid/flyash (by mass), molarity of sodium hydroxide, liquid ratio sodium silicate to sodium hydroxide, water content of mixture, dosage of super plasticiser, mixing time, rest period prior to curing, handling time, curing temperature, curing time, curing method and age of concrete. 
Joseph Davidovits (1994) reported that, Geopolymer cement hardens rapidly at room temperature and provides compressive strength of $20 \mathrm{MPa}$ after only 4 hours at $20^{\circ} \mathrm{C}$ and the 28 day strength in the range of 70 100MPa. Mallikarjuna and Gunneswara (2015) investigated that combination of flyash and GGBS resulted in decreased final setting time and increased mortar compressive strength.Ubolluk and Chindaprasirt (2009) reported that mixing sequence had some effects on geopolymerisation and strength of mortar. SEM studies suggested that geopolymerisation started with gel formation in colloidal form varying in sizes from less than $1 \mu \mathrm{m}$ to about $20 \mu \mathrm{m}$. As more gel was formed, it overwhelmed remaining flyash particles and formed a continuous mass of gel resulting in relatively dense geopolymer matrix.Mallikarjuna Rao and Gunneswara Rao (2015) observed that increase in sodium hydroxide increases compressive strength of geopolymer mortar made of combination of flyash and GGBS.

Fernando et al (2007) reported that the mud based binders possess extremely high tensile strength in 7 days of curing. Heah et al (2012) studied the kaolin-based geopolymers and concluded that kaolin geopolymers showed good volume stability with no crack and disintegration in water which proved the existence of bonding.Zhu Pan and et al (2009) reported that the strength of mortars after the exposure to elevated temperature $\left(800^{\circ} \mathrm{C}\right)$, some times decreased but other times increased. It is believed that the two opposing processes occur in mortars that (i) further geopolymerisation and/or sintering at elevated temperatures leading to strength gain and (ii) the damage to the mortar due to thermal incompatibility arising from nonuniform temperature distribution. The economic benefits and contribution of geopolymer concrete to sustainable development have been outlined (Sourav et al, 2014) and it is realised that no Indian Standards are available and so a detailed study on the chemistry behind the polymerization is needed.

\section{Experimental Investigation}

Low calcium flyash (ASTM Class F) collected from Mettur Thermal power station (Coal based) is used as the source material. The composition of the flyash and cement (OPC 43) is shown in Table 1.For its wide availability and less expensive, the sodium based solution is used as the alkaline activator shown in figure 1. The $8 \mathrm{M}, 10 \mathrm{M}, 12 \mathrm{M}, 14 \mathrm{M}$ and $16 \mathrm{M}$ molar concentration of Sodium hydroxide with liquid ratios 1.5, 2.0, 2.5 and 3.0 are considered for the preparation of alkaline solution. For each mix of the alkaline solution, the solution is mixed 24 hours prior to use. The mass of $\mathrm{NaOH}$ solids is $262 \mathrm{gms} / \mathrm{kg}$ of $\mathrm{NaOH}$ solution.Knowing the molecular weight of $\mathrm{NaOH}(40)$ and with the decided molar concentration (8M, etc.,), the weight of $\mathrm{NaOH}$ solids required per liter of solution is Mole $\times$ Molecular weight $=8 \times 40=320 \mathrm{gm}$. Similarly, the details for other molarities are given in Table 2 (Rangan, 2008). Based on the liquid ratio, the quantity of sodium silicate is also calculated.

Table 1 Chemical Composition of low calcium flyash and cement

\begin{tabular}{|l|l|l|l|l|l|l|l|l|l|l|}
\hline \multirow{2}{*}{ Material } & \multicolumn{2}{l|}{ Mass (\%) of various elements } \\
\cline { 2 - 11 } & $\mathrm{SiO}_{2}$ & $\mathrm{Al}_{2} \mathrm{O}_{3}$ & $\mathrm{Fe}_{2} \mathrm{O}_{3}$ & $\mathrm{CaO}$ & $\mathrm{Na}_{2} \mathrm{O}$ & $\mathrm{K}_{2} \mathrm{O}$ & $\mathrm{TiO}_{2}$ & $\mathrm{MgO}$ & $\mathrm{SO}_{3}$ & $\mathrm{LOI}$ \\
\hline Flyash & 54.40 & 25.64 & 11.32 & 02.03 & 00.41 & 00.73 & 01.53 & 00.92 & 01.70 & 01.32 \\
\hline Cement & 22.60 & 04.30 & 02.30 & 64.30 & 00.05 & 00.04 & - & 02.20 & 02.10 & 02.10 \\
\hline
\end{tabular}



Fig. 1 The constituents of alkaline solution

Table 2 Mass of NAOH solids in various molar solutions

\begin{tabular}{|l|l|l|l|}
\hline No & Molarity of NaOH & $\begin{array}{l}\text { Mass of NaOH solids per kg of NaOH } \\
\text { solution(gm) }\end{array}$ & $\begin{array}{l}\text { Mass of NaOH solids per } \\
\text { litre of solution }(\mathbf{g m})\end{array}$ \\
\hline 1 & $8 \mathrm{M}$ & 262 & 320 \\
\hline 2 & $10 \mathrm{M}$ & 314 & 400 \\
\hline 3 & $12 \mathrm{M}$ & 361 & 480 \\
\hline 4 & $14 \mathrm{M}$ & 404 & 560 \\
\hline 5 & $16 \mathrm{M}$ & 444 & 640 \\
\hline
\end{tabular}


The determination of the consistency of the flyash based geopolymer paste is first considered as per IS:4031-1988(Part-4), using Vicat's apparatus. The cement with water and flyash with alkaline solutions are separately dealt respectively. The standard consistency for various molar concentrations and liquid ratios are presented in Table 3.

Table 3 Consistency of paste

\begin{tabular}{|c|c|c|c|c|c|c|}
\hline \multirow[t]{3}{*}{ No } & \multirow{3}{*}{$\begin{array}{l}\text { Molarity } \\
\text { of } \mathrm{NaOH}\end{array}$} & \multicolumn{5}{|c|}{ Consistency of paste } \\
\hline & & \multicolumn{4}{|c|}{ GP with various liquid ratios of alkaline solution } & Cement \\
\hline & & 1.5 & 2.0 & 2.5 & 3.0 & \multirow[t]{6}{*}{$29 \%$} \\
\hline 1 & $8 \mathrm{M}$ & $30 \%$ & $30 \%$ & $30 \%$ & $30 \%$ & \\
\hline 2 & $10 \mathrm{M}$ & $31 \%$ & $31 \%$ & $31 \%$ & $31 \%$ & \\
\hline 3 & $12 \mathrm{M}$ & \multirow[t]{2}{*}{$32 \%$} & \multirow[t]{2}{*}{$32 \%$} & \multirow[t]{2}{*}{$32 \%$} & \multirow[t]{2}{*}{$32 \%$} & \\
\hline 4 & $14 \mathrm{M}$ & & & & & \\
\hline 5 & $16 \mathrm{M}$ & $33 \%$ & $33 \%$ & $33 \%$ & $33 \%$ & \\
\hline
\end{tabular}

Samples of flyash and sand used are shown in figure 2. Standard mortar (1:3) is prepared by taking about $555 \mathrm{gm}$ of standard sand and $185 \mathrm{gm}$ of flyash and mixing with alkaline solution (one fourth of the consistency plus $3 \%$ by combined weight of sand and flyash). The mortar is then filled into the standard cube moulds (70.7mm size) and compacted well in vibrator. In the next day, after 24 hours of casting, a set of specimens are kept in an oven for hot curing at $65^{\circ} \mathrm{C}$ for 24 hours and another set specimens of same batch under ambient curing at room temperature. Totally about twenty different mixes of GPC and one mix of conventional 43 grade cement are considered.

The mortar cubes are tested (figure 3) in 3 and 28 days of casting for hot curing and on 28 days for ambient curing appropriately after rest period. In parallel, mortar compressive strength based on conventional 43 grade OPC is also obtained. The test results of ambient curing is presented in figure 4 and that of hot cured is given in figure 5. The comparison of mortar compressive strength of ambient cured and hot cured samples is presented in figure 6 .

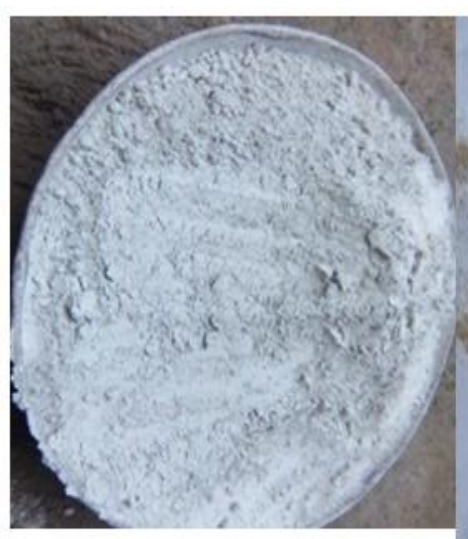

Fig.2 Samples of flyash and sieved sand

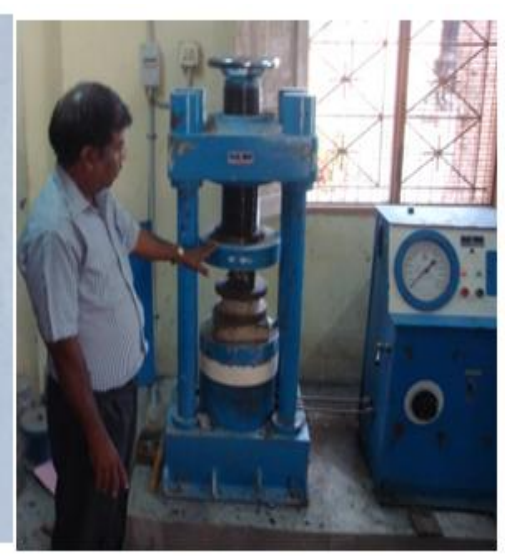

Fig.3 Testing of cubes

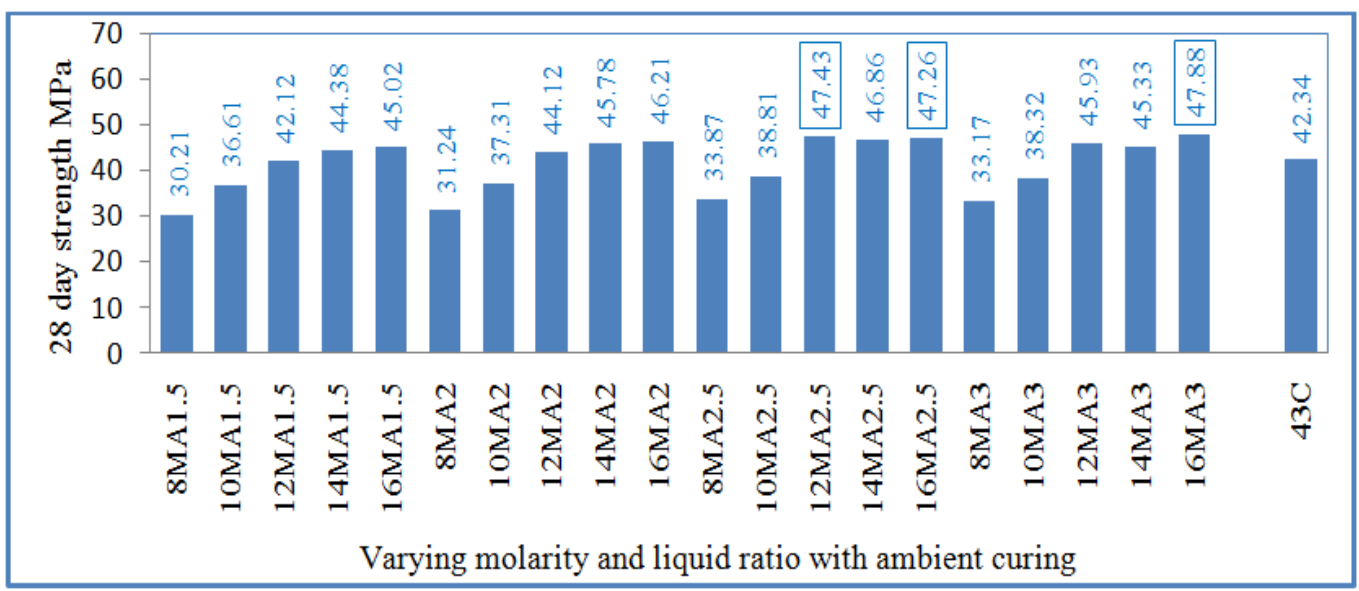

Fig.4 Comparison of strength for ambient cured mortar 


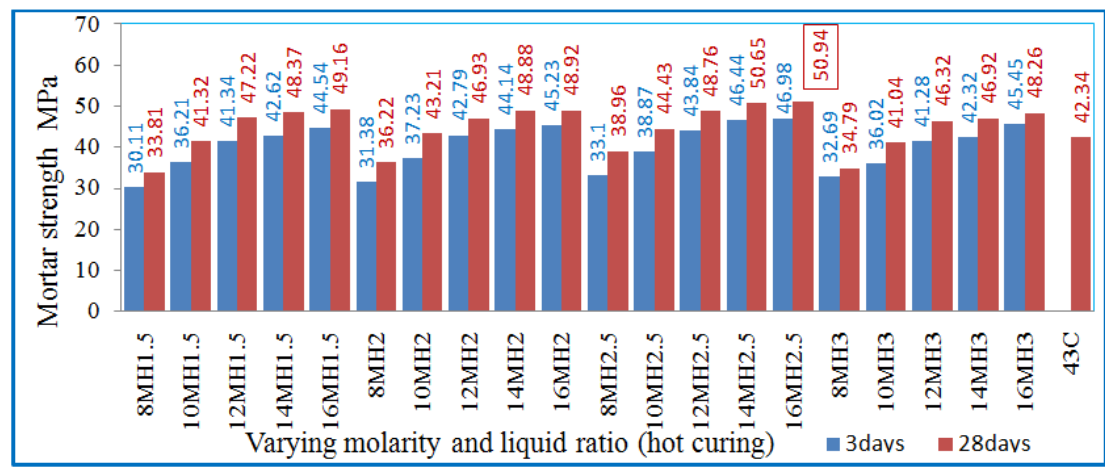

Fig.5 Comparison of strength for hot cured mortar

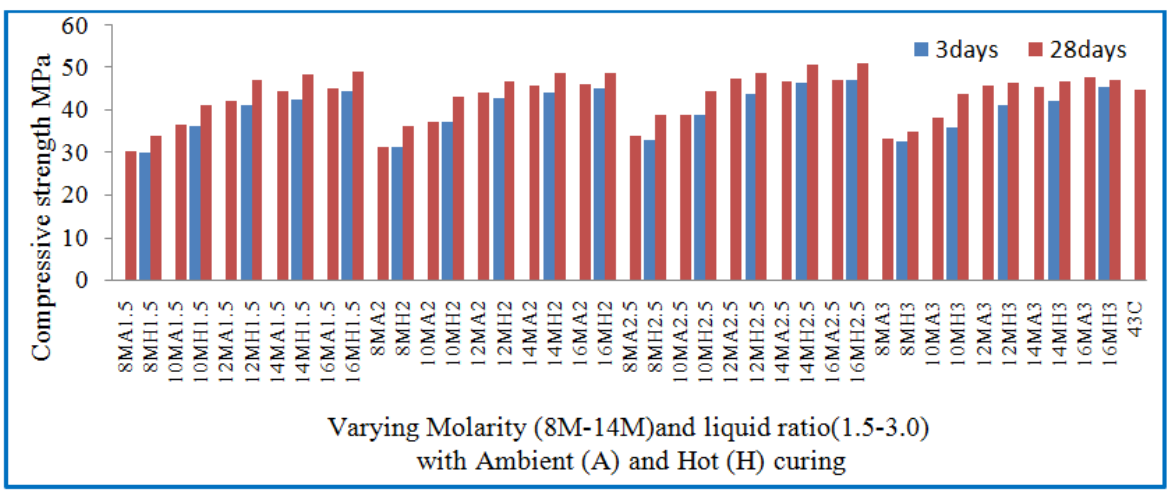

Fig.6 Comparison of strength for hot and ambient cured mortars

\section{Discussion Of Results}

$>$ The calculated amount of activator is sufficient for making a paste and no extra water is added for all the ten different concentrations of activating solution.

$>$ For hot curing both the 3day strength and 28 day strength increase with the increase in the molarity of $\mathrm{NaOH}$ for all the four liquid ratios considered. The difference between the 3day and 28 day strength is a variant. The variation is a minimum of $6.2 \%$ to a maximum of $17.7 \%$.

$>$ The maximum 3day compressive strength is achieved by hot curing for $16 \mathrm{M} \mathrm{NaOH}$ with liquid ratio 2.5 as $46.98 \mathrm{MPa}$ for which the corresponding 28 day strength is $50.94 \mathrm{MPa}$. The increase is only about $8.4 \%$.

$>$ The 28 day mortar strength is exceeded from $12 \mathrm{M}$ and above concentration of sodium hydroxide for liquid ratio 1.5 and $10 \mathrm{M}$ and above for liquid ratios 2.0-3.0 considered for hot curing.

$>$ In case of ambient curing, the three day strength is not achieved for all the 10 cases and the 28 day strength is always less compared to corresponding hot cured specimen strength. The maximum 28 day compressive strength is achieved from the ambient cured samples for $16 \mathrm{M} \mathrm{NaOH}$ with liquid ratio 3 as $47.88 \mathrm{MPa}$. This is $6 \%$ less than the 28 day strength of hot cured mortar.

$>$ The 28 day mortar strength is exceeded from 14M and above concentration of sodium hydroxide for liquid ratio 1.5 and $12 \mathrm{M}$ and above for liquid ratios 2.0-3.0 considered for ambient curing.

\section{Conclusion}

$>$ The consistency of geopolymer is proportional to the molarity of $\mathrm{NaOH}$ but independent of the alkaline liquid ratio considered.

$>$ In case of ambient curing, the 3day strength is not achieved for all the 10 cases and the 28 day strength is always less compared to that corresponding to hot cured specimens.

$>$ By hot curing, the equivalent mortar strength can be achieved using activator having $12 \mathrm{M}$ sodium hydroxide with liquid ratio 1.5 .

$>$ Equivalent mortar strength of geopolymer can be obtained using activator having 14M sodium hydroxide with liquid ratio 1.5 by ambient curing.

\section{Acknowledgement}

The authors wish to acknowledge Professor Dr.Rm.Senthamarai, Head of the Department, Dr.S.Thirugnanasambantham, Associate professor, Department of Civil and Structural Engineering, Annamalai University, for the suggestions and encouragement given to take up the research. 


\section{Reference}

[1]. Abhishek, HN and Aswath, M.U (2012). Strength studies of red mud based geopolymer concrete, International Journal of Emerging Trends in Engineering and Development (ISSN 2249-6149), 2 (6):10-32.

[2]. Ashley Russell Kotwal, Yoo Jae Kim, Jiong Hu and Vedaraman Sriraman (2015). Characterization and early age physical properties of ambient cured geopolymer mortar based on class C flyash, International Journal of Concrete Structures and Materials, 9(1): 35-43

[3]. Davidovits, J and M. Morris (1988). The Pyramids: An Enigma Solved, Chapter I, Hippocrene Books, New York( ISBN 0-87052559-X).

[4]. Djwantoro Hardjito., Steenie E. Wallah., Dody M.J. Sumajouw and Rangan, B.V. (2003). Geopolymer Concrete: Turn Waste Into Environmentally Friendly Concrete, Keynote Paper: International Conference on Recent Trends in Concrete Technology and Structures, INCONTEST 2003, 10-11 September, Coimbatore, India, pp. 1-12.

[5]. Fernando Pacheco-Torgal., João Castro-Gomes and Said Jalali (2007). Investigations about the effect of aggregates on strength and microstructure of geopolymeric mine waste mud binders, Cement and Concrete Research, 37: 933-941.

[6]. Heah, C.Y., Kamarudin, H., Mustafa Al Bakri, A.M., Bnhussain, M., Luqman, M., KhairulNizar, I., Ruzaidi, C.M and Liew, Y.M(2012). Study on solids-to-liquid and alkaline activator ratios on kaolin-based geopolymers, Construction and Building Materials, 35: 912-922.

[7]. Huihong Liu, Zhean Lu and ZiqiangPeng (2014).Test research for basic mechanics performance of inorganic polymer concrete, Research Journal of Applied Sciences, Engineering and Technology 7(2): 269-274.

[8]. IS: 4031(Part-4)-1988 (Reaffirmed-2005). Methods of physical tests for hydraulic cement: Part 4 Determination of consistency of standard cement paste,Bureau of Indian Standards, New Delhi, India.

[9]. IS: 3812-1981. India Standard Specification for Flyash for use of Pozzolana and Admixture, Bureau of Indian Standards, New Delhi, India.

[10]. Joseph Davidovits (1994). Properties of geopolymer cements, Proceedings, First International conference on Alkaline cements and concretes, Scientific Research Institute on Binders and Materials, KIEV State Technical University, Kiev, Ukraine, pp.131-149.

[11]. Joseph Davidovits (2011). Geopolymer Chemistry and Applications, 3rd edition, Institut Géopolymère, 16-Rue Galilée, F-02100 Saint-Quentin, France, www.geopolymer.org, ISBN: 9782951482050.

[12]. Mallikarjuna Rao, G and Gunneswara Rao, T. D(2015). Final Setting Time and Compressive Strength of Flyash and GGBSBased Geopolymer Paste and Mortar, Arabian Journal for Science and Engineering, 40(11):3067-3074.

[13]. Parthiban. K and Saravana Raja Mohan. K(2014). Effect of sodium hydroxide concentration and alkaline ratio on the compressive strength of slag based Geopolymer concrete, International Journal of ChemTech Research, CODEN (USA): IJCRGG ISSN: 09744290, 6(4): 2446-2450.

[14]. Prinya Chindaprasirt, Ubolluk Rattanasak and Sompop Taebuanhuad (2013). Resistance to acid and sulfate solutions of microwave-assisted high calcium fly ash geopolymer, Materials and Structures, 46 (3):375-381.

[15]. Rangan, B.V (2008). Flyash based geopolymer concrete, Research Report GC4, Engineering Faculty, Curtin University of Technology, Perth, Australia.

[16]. Shankar Sanni and Khadiranaikar RB (2012). Performance of geopolymer concrete under severe environmental conditions, International Journal of Civil and Structural Engineering, 3(2):396-407.

[17]. Shetty, M.S(2009). Concrete Technology-Theory and Practice, Chand and Company Ltd., New Delhi.

[18]. Sourav Kr. Das., Amarendra Kr. Mohapatra and A.K. Rath(2014). Geo-polymer Concrete-Green Concrete for the Future-A Review, International Journal of Civil Engineering Research, ISSN: 2278-3652, 5(1): 21-28.

[19]. Ubolluk Rattanasak and Prinya Chindaprasirt (2009). Influence of NaOH solution on the synthesis of fly ash geopolymer, Minerals Engineering, 22: 1073-1078.

[20]. Zhu Pan., Jay G. Sanjayan and Rangan, B.V(2009). An investigation of the mechanisms for strength gain or loss of Geopolymer mortar after exposure to elevated temperature, Journal of Material Science, 44:1873-1880. 